\title{
Del yo al ethos: el polifacético Lucio V. Mansilla ante el habla de los ranqueles*
}

\author{
Danielle Zaslavsky ${ }^{1}$ \\ El Colegio de México, México
}

\begin{abstract}
Resumen
El presente artículo aborda las representaciones del mundo araucano que da el coronel Lucio V. Mansilla en su conocido relato de viaje Una excursión a los indios ranqueles, publicado en Buenos Aires en 1870. El análisis descansa en un enfoque discursivo y argumentativo e indaga, mediante los distintos ethos construidos lo largo del relato, el de etnógrafo, filólogo, político, militar y literato, cómo, a través de su descripción del mundo indígena, Mansilla busca denunciar la dicotomía barbarie-civilización. La observación de las interacciones discursivas que se dan entre los ranqueles lo lleva a establecer analogías entre estas y las modalidades del discurso político del mundo "civilizado", que revelan una sutil aprehensión del lenguaje en todas sus dimensiones. Mediante una descripción que podría ser la de un analista contemporáneo del discurso, Mansilla convierte a los ranqueles en hombres equiparables a cualquier político argentino. Sin embargo, el universo discursivo de Mansilla, que es el de un político culto y letrado de su tiempo, y el auditorio variopinto al que se dirige, produce irremediablemente una visión muy heterogénea
\end{abstract}

Este trabajo se inscribe en el proyecto FONDECYT Regular 1170419 "Mediación lingüístico-cultural y castellanización en los ámbitos de contacto mapudungun-castellano derivados del proceso de chilenización de la Araucanía: producción lingüística y etnográfica, administración de justicia y escolarización (1880-1930)" (CONICYT, Gobierno de Chile).

1 Para correspondencia, dirigirse a: Danielle Zaslavsky (dzasla@colmex.mx), Camino al Ajusco 20, Pedregal de Santa Teresa, Ciudad de México, 10740, México. 
de este mundo indígena al que quiere de alguna manera proteger del exterminio que se avecina.

Palabras clave: Mansilla, indio, civilización, discurso, ethos, lector, polifonía.

\title{
From I to ethos: the multifaceted Lucio V. Mansilla REGARDING THE RANQUELE'S SPEECH
}

\begin{abstract}
This article examines the representations of the Araucanian world in Lucio V. Mansilla's Una excursión a los indios ranqueles, a travel story published in Buenos Aires in 1870. Drawing on a discursive and argumentative approach, the article analyses and explores how, via the different ethos set out in the story, e.g. that of the ethnographer, the philologist, the politician, the soldier and the literary man; as well as through his description of the indigenous world, Mansilla tries to denounce the dichotomy barbarism-civilization. Based on his own experience with the Ranquele Indians, Mansilla establishes a series of analogies between the discursive interactions of the Ranqueles and the political modalities of the "civilized" world, that reveals a subtle understanding of all the language dimensions. In his description, which could be that of a contemporary discourse analyst, the Ranqueles are portrayed as being on par with any Argentinean politician. However, Mansilla's discursive universe, which is that of a cultured and literate politician of his time, and the mixed audience he targets, result in a rather heterogeneous vision of the indigenous world whose impending extermination he is trying to prevent.
\end{abstract}

Keywords: Mansilla, indio, civilization, discourse, ethos, reader, polyphony.

Recibido: $28 / 01 / 20$

Aceptado: 23/03/20

INTRODUCCIÓN

El trabajo que proponemos a continuación descansa en un conocido relato de viaje, Una excursión a los indios ranqueles, de Lucio V. Mansilla, publicado a lo largo de 1870 en el diario argentino La Tribuna de Buenos Aires y convertido en libro este mismo año. La obra no solo fue exitosa entre los 
lectores argentinos, sino que recibió una mención honorífica en el Congreso Internacional de Ciencias Geográficas, reunido en París en 1875. El texto de Mansilla ha sido objeto de múltiples estudios que permiten apreciar la sorprendente versatilidad de este político y literato de renombre, y entender por qué este relato se convirtió en un texto emblemático de la literatura argentina del XIX.

No nos corresponde ahondar en las cualidades estético-literarias de Una Excursión a los indios ranqueles. Lo que nos interesa abordar en el presente artículo es el tipo de datos lingüísticos y etnográficos que el texto ofrece y las estrategias argumentativas desplegadas por el autor a fin de convencer a sus múltiples lectores - políticos, ciudadanos, científicos- de la calidad de sus observaciones por una parte y por otra, de la universalidad de ciertos comportamientos político-discursivos, al describir a la comunidad indígena en sus interacciones y sus procesos de negociación política.

Son estas estrategias argumentativas las que nos proponemos analizar aquí, que nos permiten entender cuál es el universo discursivo en el que se mueve Mansilla y al que, de alguna manera, intenta oponerse para revertir la representación que se tiene en aquel entonces del universo indígena. Asimismo, nos interesa destacar el asombroso modernismo de Mansilla en su observación de las interacciones discursivas que se dan entre los ranqueles, así como las analogías que establece entre estas y las modalidades del discurso político del mundo "civilizado", que revelan una sutil aprehensión y comprensión del hecho discursivo y de "lo que hablar quiere decir"2.

El presente trabajo se divide en tres grandes secciones: una contextualización del relato de Mansilla; un análisis de los datos lingüísticos y discursivos de los ranqueles en parlamento; y finalmente un análisis de las estrategias argumentativas desplegadas por Mansilla ante sus lectores.

\section{UNA OBRA Y UN AUTOR POLIFACÉTICOS}

La visita de Mansilla a los indios ranqueles se debe a una misión militar, solicitada por el presidente de la República Argentina, Domingo F. Sarmiento. En 1870, el nombre de Lucio V. Mansilla, heredero de la élite política del

2 Bourdieu, Pierre, 1982, Ce que parler veut dire, Paris, Fayard; traducido al español como Lo que significa hablar, Madrid, Akal, 1985. 
país, se conoce tanto en el ámbito periodístico, como en el político y militar. Colabora en varios periódicos de la región, ha sido diputado y es un militar experimentado, aunque inestable. Si bien esta versatilidad es relativamente común entre los intelectuales y políticos de su época, la figura de Mansilla no deja de ser sorprendente. Al parecer, el individuo tenía una "extraordinaria resistencia física y capacidad de trabajo" (Popolizio 1966: 11-12) y llegó a gozar de cierta popularidad entre los soldados del ejército argentino, pese a un comportamiento a veces juzgado como arbitrario e intempestivo que acabará por costarle el mando. Cuando viaja a territorio ranquel, el coronel Mansilla, en aquel entonces Comandante de Fronteras, toma la iniciativa de firmar un tratado de paz con el cacique Mariano Rosas (Caillet-Bois 1947: XXI), a fin de aislar política y militarmente a Kallfükura (Marimán 2006), uno de los caciques más combativo y renuente de la región a negociar su territorio con el gobierno de la república ${ }^{3}$. El relato de esta negociación, a su regreso de la Pampa, constituye la trama de Una excursión a los indios ranqueles ${ }^{4}$.

Después de su salida forzada del ejército -la ruptura con Sarmiento será definitiva-, pero no de la vida política del país, pues Mansilla suele acomodarse con varios gobiernos en turno, el hombre sigue viajando y escribiendo ${ }^{5}$, siendo el viaje la condición misma de su escritura (Contreras 2012). Muere en 1913 a la edad de 81 años en Francia, país donde se había radicado y estudiado en su juventud después del destierro de su padre.

Independientemente del éxito que tuvo entre los lectores de la Tribuna (Popolizio 1966: 12), el que el texto haya gozado de suficiente legitimidad para merecer una mención honorífica en la Société Française de Géographie en la década de su publicación, no deja de ser ejemplar. Cabe precisar que Mansilla no es el único literato de la época en mandar sus textos a dicha institución. Así lo harían otros viajeros de renombre como Arthur Rimbaud o el arqueólogo Heinrich Schlieman, que buscarán, en su calidad de exploradores, no solo un reconocimiento de la Sociedad de Geografía,

\footnotetext{
En varias partes del relato, Mansilla evoca el proyecto de un tren que atravesaría el territorio indígena.

4 El tratado no fue aceptado como tal por el Presidente de la República, y se tuvo que firmar otro tratado en 1872 en el que Mansilla ya no participó, el último de los parlamentos en este territorio antes de la intervención militar de Roca en los años 80 .

5 Según Caillet-Bois, los amigos de Mansilla estimaban que la recopilación completa de su obra necesitaría más de un centenar de volúmenes (Caillet-Bois 1947:XXXI). Varios de sus relatos diseminados en periódicos de la época han sido recopilados en años recientes. Ver Lucio V. Mansilla, El excursionista del planeta; escritos de viaje. Selección y prólogo de Sandra Contreras, Buenos Aires, FCE, 2012.
} 
institución de mucho prestigio a nivel internacional, sino un eventual apoyo financiero. (Louis 2007)

En el caso específico de Mansilla, el premio otorgado parece coronar la curiosidad inagotable de un individuo apasionado por el viaje, lo desconocido y el contacto con la otredad, en este caso los indios ranqueles, hacia quienes "proyecta una mirada antropológica desprovista de exotismo, similar a la que proyecta hacia los franceses, los alemanes, los ingleses, los argentinos, desmontando de este modo tanto el racismo positivista de la época como el racismo evolucionista" (Louis 2007: 441). Esta mirada, "desprovista de exotismo" es la que probablemente atrajo a los evaluadores del concurso. Así como lo menciona Annick Louis en su artículo (Louis 2007: 453), el nombre de Mansilla aparece en dos ocasiones, pero en fragmentos relativamente escuetos. Los evaluadores del grupo III de antropología formulan:

M. Uricoechea est malheureusement le seul exposant américain qui ait apporté à notre exposition des documents d'un haut intérêt. Les salles consacrées aux produits du Chili et de la République Argentine ne contiennent qu'un petit nombre d'opuscules qui nous intéressent directement, et parmi lesquels nous mentionnerons les documents ethnographiques sur le Chili de M. de Barros Arana, et de M. Mansilla sur la République Argentine.

Algunas páginas más adelante, en la sección del grupo IV de etnología, se lee:

Dans la République Argentine, le rapporteur doit signaler, au nom du groupe IV, un travail méritant; $M$. Mancillia (sic) nous fournit une intéressante description de son Excursion chez les Indiens Ranqueles, que nous croyons devoir récompenser d'une mention honorable ${ }^{6}$.

Tanto Barros Arana sobre Chile como Mansilla "sur la République Argentine" se mencionan en la sección "Républiques américaines" del informe del grupo III. Aparte de la "mention honorable" otorgada por el grupo IV para Mansilla, gracias a "una interesante descripción de su Excursión a los indios ranqueles", estas pocas líneas confirman que su texto se recibió y definió como un documento etnográfico ${ }^{7}$. De alguna manera, es lo que pretende

\footnotetext{
6 Congrès International des Sciences géographiques, tenu à Paris du 1 au 11 août 1875 : compte rendu des séances. 1880, volume second, BNF, pp. 322; 340. Fuente: gallica.bnf.fr / Bibliothèque nationale de France

7 El nombre de Mansilla vuelve a aparecer de la siguiente manera en la última sección del volumen, en la que se recopilan todos los premios otorgados por grupo. "M. MANCILLA. Excursions chez les Indiens Ranqueles, 2 vol. 1870-1871 (République Argentine). Entre
} 
también el propio Mansilla, al formular en la dedicatoria que inicia su texto: "el deseo de ver con mis propios ojos ese mundo que llaman Tierra Adentro, para estudiar sus usos y costumbres, sus necesidades, sus ideas, su religión, su lengua, e inspeccionar yo mismo el terreno por donde alguna vez quizá tendrán que marchar las fuerzas que están bajo mis órdenes (...)". (I-3)

Este estudio del mundo ajeno, Mansilla lo va a realizar desde variadas escenificaciones de su yo frente al otro indígena, que oscilaran entre el yo autoritario (Molloy 1996), el de un jefe militar que tiene "fuerzas bajo sus órdenes" y el yo de un viajero-etnógrafo, cuya capacidad de observación va mucho más allá del arquetipo del "gentleman-militar" (Viñas 1982), pero que está todavía muy alejado del yo de un científico, como lo veremos en las páginas siguientes. La omnipresencia del "yo" de Mansilla en sus obras está subrayada por la mayoría de los comentaristas y estudiosos consultados (Viñas 1982; Ramos 2012; Caillet-Bois 1947; Popolizio 1966; Historia de la literatura argentina, 1980-1986; Molloy 1996; Feldman 2010; Salvioni 2015 , entre otros). Quisiéramos en las siguientes páginas retomar este yo desde las teorías de la argumentación, convertirlo en ethos, en varios ethos, en ocasiones explícitos, mediante los cuales Mansilla busca convencer a su auditorio de la legitimidad de su discurso.

\section{DEL YO AL ETHOS}

La noción de ethos, que proviene de la retórica de Aristóteles, consiste en dar una imagen de sí capaz de convencer al auditorio, en el mismo proceso

las 21 "menciones honoríficas" otorgadas por el grupo IV, Mansilla es el único premiado hispanoamericano. Si bien el título de la obra, que consta de dos volúmenes, está en francés, es probable que se recibiera y leyera en español, dada la insistencia de los organizadores del congreso en la multiplicidad de lenguas que en este se intercambiaron (ver en particular p. 389).

8 De ahora en adelante, todas las citas de la obra de Mansilla provienen de la edición del Fondo de Cultura Económica, publicada en 1947, y prologada por Julio Caillet-Bois: Mansilla, Lucio V., 1947 [1890] Una excursión a los indios ranqueles, Fondo de Cultura Económica, México, Buenos Aires. Esta edición recoge la edición de 1890, la tercera en vida de Lucio V. Mansilla y revisada íntegramente por él (nota de la edición del FCE). Las citas vendrán referenciadas de la siguiente manera: I-3, XX-128, etc., es decir, la cifra romana del capítulo y la paginación correspondiente. Como la paginación del prólogo de Caillet-Bois se encuentra en números romanos, la dejamos tal cual. (Caillet-Bois 1947: XXVIII) 
de enunciación. "El destinatario debe atribuir así ciertas propiedades a la instancia propuesta como el origen del acontecimiento enunciativo" (Maingueneau 2010: 205). El ethos fue retomado primero por Roland Barthes, luego por Oswald Ducrot, y ampliamente desarrollado por los seguidores de la Nueva retórica de Perelman y las teorías de la enunciación, en especial Ruth Amossy y Dominique Maingueneau. El ethos "se muestra en el acto de enunciación, no se dice en el enunciado" (Maingueneau 2010: 206) y tiene que ver con la imagen que da de sí mismo un locutor ante un auditorio, fenómeno que en sí mismo sería bastante trivial, si no estuviera íntimamente vinculado con la escena de enunciación ${ }^{9}$. Paulatinamente, estos mismos investigadores crearon el concepto de ethos prediscursivo/ previo (Amossy 1999; 2010; Maingueneau 1999), partiendo del principio de que el auditorio siempre tiene cierta imagen del enunciador que toma la palabra, la cual incide forzosamente en la imagen que busca dar de sí el locutor al momento de la enunciación. En años más recientes, Maingueneau hará hincapié en otra dimensión del ethos, el "ethos dicho" (Maingueneau 2014), lo que formula el locutor de sí mismo, dimensión que la problemática inicial había relegado en segundo plano. Patrick Charaudeau, al centrarse en el discurso político, distingue entre varios tipos de ethos, que funcionan como "máscaras del poder" regidos por dos ejes principales, la legitimidad y la credibilidad del actor político (Charaudeau 2005) ${ }^{10}$. Por más compleja y diversificada que sea la noción de ethos hoy en día, esta herramienta sigue siendo muy útil, sobre todo cuando se trata de identificar las estrategias argumentativas desplegadas por un autor tan egocentrado y polifacético como Mansilla. En otras palabras, no se trata de limitar la emergencia del yo, bajo todas sus formas, a la expresión de la subjetividad de Mansilla - $\mathrm{O}$ de su ego-, sino de entender cómo se utiliza con fines persuasivos. Veremos a continuación los distintos tipos de ethos desplegados por Mansilla a lo largo de su texto.

\footnotetext{
9 Maingueneau concibe la escena de enunciación en "tres dimensiones": 1) una escena envolvente -estatus, tipo de acontecimiento, contexto; 2) una escena genérica que apunta hacia el género discursivo en el que toma cuerpo el texto; 3) una escenografía, la que el discurso mismo va construyendo, tanto en cuanto a contexto como en cuanto a identidades de los participantes.

10 Ver al respecto la excelente presentación de Maritza Nieto y Pablo Segovia (2018), sobre la problemática del ethos desde la perspectiva francesa.
} 


\subsection{El ethos Del Mansilla Viajero}

Una excursión a los indios ranqueles se inscribe, como bien se sabe, en el género de la literatura de viaje, pero en ruptura con esta. El relato "con amenidad de novela" (Popolizio 1966: 12), comparte muchos rasgos de la literatura tradicional de viaje como la intertextualidad (Albuquerque 2011), esa "dimensión heteroglósica" que crea a sus propios destinatarios, los "travelees" (Pratt 1992: 134) 11 , pero va más allá al proponer "por un lado, la vitalización de la norma estética de su época y, con el mismo movimiento, la literaturización de los discursos testimoniales de la experiencia vivida" (Ramos 2012: 75). Contrariamente a lo que observa Pratt (1992), para muchos viajeros de la primera mitad del siglo, relatos en el que el viaje en sí mismo constituye el reto mayor, "What are conquered are destinations, not kingdoms; what are overcome are not military challenges, but logistical ones" (Pratt 1992: 148), Mansilla logra combinar un relato de la extrañeza, a veces inhóspita, pero cautivadora, con el de una misión político-militar. La obra, según Julio Ramos, constituye la "inversión" de un viaje a Europa, tradicional entre los letrados de la época, "un deliberado viaje a la barbarie", es más, "un nuevo tipo de ejercicio turístico" (Ramos 2012: 74;). Algunos, como Viñas, lo inscriben en la literatura de frontera, incluso en la literatura castrense. "Una excursión a los indios ranqueles es la forma superior del contenido de una forma inferior que es la literatura de frontera. Resulta melancólico, por cierto: Mansilla logra convertir en literatura un material de "comunicados" sobre el despojo. Es que la palabra hace pie en la energía de la literatura castrense" (Viñas 1971:28). Regresaremos más adelante sobre el despojo que efectivamente Mansilla logra denunciar con fuerza y habilidad. Ahora bien, aunque la Excursión se presenta en algunas páginas como una literatura de "hombres a caballo", al "estilo de los partes", producido efectivamente por una abundancia de verbos en primera persona de plural, como "salimos", "anduvimos", "cruzamos" (Viñas 1971: 31) que marcan los movimientos en un espacio escrupulosamente representado -Mansilla está en misión militar y sabe de mapas- ${ }^{12}$, el abundante material que recoge

11 Pratt crea en este caso un neologismo interesante, inspirado por el concepto discursivo de "adressee", explicando que los teóricos de la literatura crearon el concepto de "narratee", destinatario específico de la narración. (Pratt 1992: 242)

12 Sobre la función del mapa elaborado por el propio Mansilla en la primera edición de su libro, véase Salvioni Amanda 2015, "El silencio de las imágenes. Las ilustraciones a Una excursión a los indios ranqueles", Confluenze, vol. 7, n 1, Bologna. En línea, https// confluenze.unibo.it 
nuestro autor sobre las prácticas discursivas de los ranqueles en parlamento y la descripción de sus propias interacciones con ellos, material caracterizado por una multiplicación de discursos referidos, de diálogos, de digresiones, de reflexiones, aplacan los partes militares, o mejor dicho, hacen de la Excursión un texto genéricamente fronterizo que puede interesar a varios tipos de lectores, entre los cuales estarán los evaluadores de la Société Française de Géographie: "Con imparcialidad de viajero establece distinciones que otros no advertirían (...) Con prolijidad de naturalista profesional apunta rasgos de un pueblo destinado a extinguirse...". (Caillet-Bois 1947: XXVIII)

Sin embargo, ni el perfil de Mansilla, ni sus aspiraciones lo destinaban a integrarse a los científicos. Independientemente de la agudeza de las observaciones de su autor, la Excursión ostenta todavía muchos de estos rasgos conversacionales, intimistas, digresiones subjetivas que podemos encontrar en los otros textos que se le conocen como Entre-nos, Causeries del jueves ${ }^{13}$ o en Mis memorias, que alejan este relato de una exposición propiamente científica, caracterizada ya en esta época por algún "distanciamiento enunciativo" (Rabatel 2004) ${ }^{14}$. Ninguno de los intentos posteriores de Mansilla, los de fin de siglo, ya sean ensayos históricos o políticos, lograrán el rigor necesario para alcanzar un mercado propiamente académico o científico (Caillet-Bois 1947: XXXII). El auditorio de Mansilla no es el de los científicos, es un auditorio variopinto, el de los lectores de $L a$ Tribuna, entre los cuales se encuentran los políticos del país.

¿A quién se dirige Mansilla?

Mansilla conversa, y su yo narrador, desmedida "inflación del yo" para retomar la expresión de Julio Ramos (Ramos 2012:80), se dirige en forma epistolar a un tú, explícitamente nombrado, Santiago, amigo cercano de Mansilla y con el cual polemiza ${ }^{15}$. Pero Santiago no es el único destinatario del texto. También está el lector: "Conviene prevenir, por la malicia del lector, que los franciscanos, según estaba acordado, hicieron su cama al lado de la mía" (XVIII-101). Los llamados al lector son comunes a muchos textos de la época. "Recuerda el lector que he copiado de un manuscrito

13 El libro Entre-nos, Causeries del jueves, que se publica en las décadas ochenta y noventa del XIX, también a partir de unas entregas regulares a un periódico, es un amalgama de recuerdos, observaciones y comentarios.

14 Varios teóricos de la enunciación, Alain Rabatel entre ellos, crearon el concepto en francés d' "effacement énonciatif", literalmente "borramiento enunciativo", para evitar la dicotomía objetivo/subjetivo, partiendo del principio de permeabilidad de todo tipo de texto por un sujeto enunciador.

15 Se trata de Santiago Arcos, intelectual chileno, que había escrito también un folleto donde relata su viaje entre los indios de la frontera con Argentina. (Ramos 2012) 
que Facundo nunca se confesaba, nunca oía misa...", leemos en Sarmiento (Sarmiento 1977: 125) ${ }^{16}$. Volvemos a encontrarlo tanto en el texto de un viajero como Reuel Smith, relato de un viaje realizado en tierra mapuche chilena a mediados del XIX y traducido por Lachtam en 1914 -"antes de seguir adelante, será mejor tal vez informar al lector de la naturaleza del gobierno araucano" (Reuel Smith 2016 [1855]: 198)- como en textos más tardíos del lingüista Lenz, -“tampoco será necesario que lean los párrafos siguientes los filólogos europeos (...). Pero invito a los lectores americanos a que me sigan un momento, para que comprendan mis propósitos"17. Las llamadas al lector ostentan distintos grados de convencionalismo con los que Mansilla juega constantemente: "Tendrás paciencia, hasta mañana, Santiago amigo, y el paciente lector contigo" (XX-111); "También conviene hacerlo así para que ni tú, Santiago amigo, ni tú lector se hastíen -que lo poco gusta y lo mucho cansa, aunque a este respecto pueden dividirse las opiniones según sea el capítulo de que se trate" (XXV-138). Al diferenciar a Santiago, lector de carne y hueso plenamente identificado, destinatario de las cartas, “También ellos reciben y leen La Tribuna. ¿Te ríes Santiago?" (X-52), de este lector abstracto, o al menos no nombrado, verdadera "instanciablanco" de su texto (Charaudeau, Patrick 2003: 103) ${ }^{18}$, Mansilla construye a varios destinatarios que un análisis detenido de las estrategias enunciativas desplegadas al filo de la narración permiten identificar (Feldman 2010; Ramos 2012). El militar-antropólogo-literato es un político que busca incidir en el escenario político argentino, y la mirada proyectada hacia estos otros que son los indios ranqueles, al construirse un ethos de etnógrafo, no solo deja entrever la medida de su desengaño con Sarmiento (Molloy 1996), sino que busca contrarrestar la masacre que se avecina. Muy al final de su texto, Mansilla, hablando "consigo mismo" en un diálogo imaginario, suelta: "Sí, tú, has entrado en un miserable toldo de un indio a quien un millón de veces has calificado de bárbaro, cuyo exterminio has preconizado en todos los tonos, en nombre de tu decantada y clemente civilización, te ves derrotado

16 Sarmiento, Domingo F., Facundo o Civilización y Barbarie, Biblioteca Ayacucho, Ayacucho, 1977 [1845].

17 Rodolfo Lenz, apud Ennis, Juan Antonio y Pfänder Stephan, 2013, Lo criollo en cuestión, Katatay ediciones, Buenos Aires, p. 141. Ennis hace hincapié en la clara preocupación de Lenz por sus lectores americanos, que está muy presente en la filología sudamericana desde A. Bello.

18 Charaudeau, Patrick 2003 [1997], El discurso de información, Gedisa, Barcelona. 
y no quieres confesar tu ignorancia (...) Sí, humíllate, y aprende una vez más que el mundo no se estudia en los libros". (LXV-368) $)^{19}$

Con todo, la profundidad con la que Mansilla aprehende la voz de los ranqueles "en su proximidad, con sus sudores, los ruidos de sus cuerpos, su saliva y hasta la forma de los lacrimales, de sus argumentos o de sus ombligos" (Viñas 1982: 152), indios que "hablan, comentan, piden, inquieren, conversan, protestan, gritan, susurran" (Salvioni 2015: 110), indios que son políticos y buscan incidir como él en este mismo escenario político, nos revela a un Mansilla fino observador del hecho discursivo en el ámbito político. Antes de detenernos en estas interacciones referidas, veamos primero cómo presenta Mansilla la lengua que hablan los ranqueles y la representación que quiere dar de ella a sus contemporáneos.

\subsection{El ETHOS DEL FILÓLOGO AMATEUR}

\subsubsection{La lengua indígena y su representación}

Los procedimientos de Mansilla para dar voz a los ranqueles son de varios tipos que merecen ser abordados. En primer lugar, inserta, mediante equivalencias explícitas, varios términos y expresiones del habla de los ranqueles, que arrojan una lengua muy parecida a la que recogen viajeros y lexicógrafos de los siglos anteriores en Chile.

Al igual que la mayoría de sus contemporáneos, el viajero suele precisar los lugares recorridos, muchos de ellos topónimos, seguidos por su traducción al castellano: "costeando el Río Quinto [la nueva frontera de Córdoba] se prolonga hasta la Ramada Nueva, llamada así por mí, y por los ranqueles, Trapalco, que quiere decir agua de Totora, Tratal es Totora, y có agua" (I-5); "El punto a donde nos dirigimos era la Laguna de Calcumuleu, que quiere decir agua en que viven brujas" (XVII-93); "Leubucó es una laguna sin interés -quiere decir agua que corre, leubú, corre y có, agua" (XXIV-131). Las equivalencias se ofrecen con relativa sencillez mediante la perífrasis "quiere decir", pero la estructura morfemática de la palabra no da lugar a mayores desarrollos. El narrador no pretende ser especialista, sino culto y leído, como en el caso siguiente:

19 Como dice Salvioni, faltaba poco para que estos mismos indios se conviertieran en el "objeto inerte del conocimiento científico por la incipiente etnografía". (Salvioni 2015: 109) 
Este cerro está cerca de Achiras, y su nombre significa en quechua, si no ando desmemoriado en mis recuerdos etnográficos y filográficos, casa del sol. Diéronselo los incas en una de sus famosas expediciones por la parte oriental de la Cordillera. Inti quiere decir sol, y guasi, casa. (XVIII- 96)

A diferencia del primer ejemplo, en el que Mansilla asume en primera persona un acto de designación "llamada así por mí", en esta última equivalencia el viajero deja ver un ethos de prudente erudito en la materia, "si no ando desmemoriado en mis recuerdos etnográficos y filográficos", al usar dos términos que buscan inscribirse en campos reconocidos como científicos, aunque el segundo término no exista como tal ${ }^{20}$. Sin embargo, nada en la explicación de estos topónimos denota un enfoque explicativo propiamente científico de nuestro viajero. Las equivalencias se dan "de paso", mostrándonos a un Mansilla atento a una toponimia cuyo significado conoce $^{21}$. Lo mismo pasa con algunos nombres propios: "Las dos hijas mayores se llamaban Comeñe, la primera, que quiere decir ojos lindos, de come, lindo, y de ñe, ojos; Pichacaiun, la segunda, que quiere decir boca chica, de pichicai, chico, y de un, boca". (LXVI- 372)

En cambio, cuando habla de la numeración en araucano, la descripción se vuelve más compleja, tal y como lo podemos observar en este pasaje:

Tenía interés en aprender a contar en lengua araucana. Me dirigí pues a Mora [el lenguaraz], aprovechando el tiempo, ya que por algunos momentos me veía libre de embajadores, mensajeros y parlamentarios y le pregunté:

¿Cómo se llaman los números en la lengua de los indios?

Mora no entendió bien la pregunta. Él sabía perfectamente bien lo que quería decir cuatro, pero ignoraba qué era número. Le dirigí la interpelación en otra forma, y el resultado fue que mis lectores mañana, y tú después, Santiago amigo, sabrá contar en una lengua más.

[sigue la enumeración de los 10 primeros números, seguidos por los números cien y mil].

Ahora cincuenta se dice quehú-mari; doscientos, epú-patacá; ocho mil, purra-barrancá; y cien mil, pataca-barranca.

Y esto prueba dos cosas:

20 La palabra adjetivada "filográficos" que aparece en todas las ediciones consultadas de la Excursión no está consignada en ningún diccionario de lengua española, si bien el sustantivo "filografía" aparece actualmente en línea para designar una representación gráfica, ya sea de algún concepto filosófico, o para referirse al grafismo de alguna escritura.

21 A ese respecto, encontramos más definiciones de topónimos en Mansilla que en los relatos de otros viajeros en tierras chilenas, como Reuel Smith o Henry Delaporte. (Salgado 2016) 
$1^{\circ}$ Que, teniendo la noción abstracta del número comprensivo de infinitas unidades, como un millón, que en su lengua se dice marí-patacabarranca, estos bárbaros no son tan bárbaros ni tan obtusos como muchas personas creen.

$2^{\circ}$ Que su sistema de numeración es igual al teutónico, según se ve por el ejemplo de quehú-mari, que vale tanto como cincuenta, pero que gramaticalmente es cinco-diez. (XXI-116) ${ }^{22}$

La dicotomía entre el tú de "Santiago amigo" y el tú de "mis lectores", -a quienes va dirigida una supuesta preocupación pedagógica- "sabrán contar en una lengua más", le permite a Mansilla construirse aquí un ethos de etnolingüista, que sabe trabajar con un informante, en este caso, su lenguaraz, formulando las preguntas de manera atinada. La descripción que se nos ofrece del sistema numérico araucano no difiere mucho de la que hiciera un B. L. Whorf (1966) desde la teoría de la relatividad lingüística medio siglo después ${ }^{23}$. Por otra parte, sugiere ya una clara distinción entre el conocimiento metalingüístico que los hablantes pueden tener de las categorías gramaticales de su propia lengua, y las posibilidades expresivas de ésta, reflexión que volveremos a encontrar en el Jakobson que formula en los años cincuenta del siglo pasado: "Las lenguas difieren esencialmente por lo que deben expresar y no por lo que pueden expresar" (Jakobson 1975). La lengua araucana es "una lengua más" entre las lenguas del mundo, ni más ni menos que ellas. No solo los datos ofrecidos en lengua indígena están por lo general desprovistos de cualquier juicio despreciativo sobre el valor de la lengua -pobre, simple, fácil-, comunes a varios humanistas de su tiempo ${ }^{24}$, sino que por el contrario busca equiparla con los sistemas lingüísticos del mundo "civilizado". Cierto es que lo hace muchas veces en modo irónico: "En lengua araucana, el acto de penetrar en un toldo a deshoras de la noche se llama cancanear y cancán equivale a seducción. Los filólogos franceses pueden averiguar si estos vocablos se lo han tomado los indios a los galos o éstos a los indios"(XXXVI-200). Si bien en este ejemplo la ironía y la comparación con la lengua francesa se debe a lo escabroso del campo

22 Todas las palabras en lengua indígena vienen en cursivas en el original. Las otras son mías.

23 Ver especificamente "The relation of habitual thought and behavior to language". (Whorf 1966: 134-160)

24 La descripción que hace Barros Arana sobre "la lengua chilena", por ejemplo, abunda en términos evaluativos: "la lengua chilena es un instrumento fácil de comprender y de manejar (...) de fácil pronunciación (...) los sustantivos no tienen más que un solo género (...) no hay más que una sola conjugación ..." (Barros Arana 1934: 51), observaciones que si bien denotan cierto conocimiento técnico, apuntan todas a cierta pobreza de la lengua respecto de las lenguas occidentales. 
semántico abordado ${ }^{25}$, la "privilegiada ironía" de Mansilla, la distancia mediante la cual puede "pronunciar una palabra de frente y reflexionar sobre ella, de inmediato, por la espalda" (Viñas 1982: 153), le permite sugerir en este improbable vaivén de las lenguas, otro despojo posible del occidente civilizado hacia los indios.

Junto con estos datos propiamente lingüísticos presentados a lo largo del texto, son innumerables las observaciones sobre los "modos de hablar" de los ranqueles, sus entonaciones, acentuaciones, interjecciones, todos estos aspectos del lenguaje humano que los estructuralistas dejarían medio siglo después fuera de su campo de estudio, pero que todos los análisis conversacionales posteriores volverían a retomar. "La gracia consiste en la más perfecta uniformidad en la entonación de las voces. Y sobre todo, en la mayor prolongación de la última sílaba de la palabra final. (...) Esta última sílaba prolongada, no es una mera fioritura oratoria. Hace en la oración los oficios del punto final" (XXI -115). Cabe mencionar que Mansilla se muestra igualmente atento a la tonada de Camilo, "el indio blanco", cautivo originario de Córdoba: "Como usia quiera (contestó el cautivo con esa tonada cordobesa que consiste en un pequeño secreto: -cargar la pronunciación sobre las letras acentuadas y prolongar lo más posible la vocal o primera sílaba" (XI-56). Sin embargo, los comentarios de Mansilla en este rubro ostentan a veces una clara connotación negativa: "concedí el permiso, y vino un diálogo como el que ya conocemos, con su multiplicación de razones, con sus últimas sílabas prolongadas a más no poder..." (XXIV-129). La acentuación de las últimas sílabas "a más no poder" se vuelve caricatural, burla que volvemos a encontrar en su propia actuación con sus contrincantes ranqueles, al final del parlamento, "Y al decir mi hermano, acentuaba la palabra cuánto podía y me dirigía a Mariano Rosas". (LIV-304)

Cuando se detiene en sonidos que no entiende, Mansilla da rienda suelta a varios comentarios peyorativos, en los que los ranqueles se vuelven bárbaros, salvajes, indios, perros, lobos, más cerca de lo animal que de lo humano: "Cuando rehusaba un yapai, gruñían como perros, ¡la cólera se pintaba en sus caras vinosas y murmuraban iracundas palabras que no podía entender... Bababababababababa!! Resonaba, ahogándose los últimos ecos en la garganta de aquellos sapos gritones" (XXXI-171). En estas descripciones de las "orgías ranqueles" en las que "el personaje del coronel queda petrificado en el gesto del brindis bárbaro" (Schvzarzman 2002: 151),

25 La carta, en todas las ediciones consultadas, lleva una nota del autor que dice: "Esta carta será mejor que no la lean las señoras". 
Mansilla abandona su ethos de etnógrafo-filólogo, para dar rienda suelta a la doxa más arraigada de la época y alcanzar de este modo otro tipo de lector, "el sujeto de la civilización" de los barrios cultos de Buenos Aires (Ramos 2012: 89). Ahora bien, cuando Mansilla describe a los ranqueles a la hora de negociar, vuelve a recuperar la distancia necesaria del observador filólogo-etnógrafo.

Las prácticas discursivas de los ranqueles descritas por Mansilla en la Excursión tienen lugar principalmente en parlamento, es decir en un contexto de negociación política interétnica entre dos fuerzas en presencia, autoridades indígenas y autoridades argentinas ${ }^{26}$.

\subsubsection{El ritual y sus agentes}

El protocolo descrito en la Excursión se antoja menos ceremonioso que los rituales que solían darse del otro lado de la cordillera (Marimán 2006: 123), pero el marco sumamente ritualizado en el que se dan los intercambios presenta varios rasgos comunes a los parlamentos consignados en Chile durante la época colonial ${ }^{27}$. En primer lugar, la teatralidad del acto $^{28}$ : aparecen los distintos personajes principales -caciques, embajadores, capitanejos, mensajeros, etc.-, la disposición precisa en el escenario de los dos bandos, cada uno de los movimientos de los participantes responde a normas precisas (XXIV; LIII). En segundo lugar, el concepto mismo de "parlamento" parece funcionar de la misma manera que en la época colonial, es decir, designa al mismo tiempo el proceso de negociación entre los dos bandos y el resultado de esta negociación, el tratado de paz. "No sé si tenéis idea de lo que es un parlamento en tierra de cristianos; y digo en tierra de cristianos, porque en tierra de indios el ritual es diferente. Un parlamento es una conferencia diplomática (II-8). Notamos sin embargo cierta ambigüedad en el uso del término, ya que Mansilla lo utiliza de repente para designar una negociación interna de los ranqueles, acepción atestada en los primeros parlamentos coloniales: "En tanto que estos parlamentos tenían lugar, muchos indios viejos, de extraño aspecto giraban en torno mío y de los míos..." (XXIV-

26 El parlamento descrito por Mansilla será el último firmado entre el gobierno argentino y el mundo indígena antes de la campaña emprendida por Roca a fines de los setentas. En Chile, el último parlamento tendrá lugar en 1882.

27 La literatura sobre los parlamentos chilenos es abundante. Ver en particular (Payàs 2012; 2018; Zavala 2008; 2011).

28 Mansilla utiliza a menudo metáforas teatrales para referirse al parlamento: "El parlamento comenzó con aquellos avisos de teatro del tiempo de Rosas que decían, después de las vivas y mueras de costumbre (iy qué costumbre más civilizada y fraternal!), se representará el lindo drama en verso de Clotilde ...". (XXVI-139) 
130). Pero estos casos de ambigüedad son poco frecuentes, y cuando Mansilla utiliza la palabra "parlamentar", lo hace en el contexto de una interacción interétnica: "Extendiendo ponchos bajo los árboles y formando rueda, nos pusimos a parlamentar entre mate y mate, entre trago y trago de aguardiente" (XVI- 87). En cambio, así como lo habíamos observado en los documentos coloniales a fines del XVIII (Zaslavsky, Payàs, Carreño 2019) se confirma la diferencia entre parlamento y junta, siendo la última consignada como práctica de reunión política interna al mundo araucano ${ }^{29}$.

En tercer lugar, se subraya la presencia obligada de varios lenguaraces, mínimamente uno por bando, sin los cuales el acto no se puede llevar a cabo. La función del intérprete en los parlamentos del periodo colonial chileno -traductor, mediador cultural- ha sido consignada en varios estudios (Payàs, Ramón Curivil et al. 2012). Sin la presencia del intérprete o lengua general que prestaba juramento al inicio del parlamento, presencia solicitada expresamente por la corona "porque, aunque yo sé la lengua, fue voluntad del señor Virrey que hablase también por intérprete" (Luis de Valdivia 1612: $73)^{30}$, el acto no se podía llevar a cabo. En términos austinianos, podríamos afirmar que la presencia del intérprete constituye una de las condiciones de felicidad para que el acto se cumpla (Austin 1982), es el garante de la performatividad de la negociación interétnica, en tanto macro acto de habla (Van Dijk 1980; Kerbrat-Orecchioni 2001). Algunos cambios, sin embargo, respecto del periodo colonial son notorios. Los lenguaraces de Mansilla ya no prestan juramento ante los representantes del rey a fin de "decir verdad y traducir fiel y legalmente cuanto el señor presidente propusiese a los indios y cuanto estos respondiesen" (Parlamento general de Negrete 1771:356), su labor se profesionaliza y la remuneración que perciben por ella está regulada (Perna 2016). Aunque en el último tercio del XIX los araucanos con los que se tiene que negociar entienden, hablan y escriben en castellano tanto en Chile como en Argentina, cada uno de los bandos se expresa en su propia

29 La palabra junta, que había alternado con la palabra parlamento para designar las negociaciones internas de las poblaciones mapuche durante el siglo XVII, acabó designando exclusivamente una práctica autóctona cuando el término parlamento se impuso como práctica de negociación interétnica, convocada por la corona, durante el siglo XVIII. Los viajeros del siglo XIX reservarán también la palabra junta a las prácticas de reunión autóctonas, como lo podemos ver en este relato de Henry Delaporte: "La junta, prácticamente, había finalizado con un llamado a las armas...". (Delaporte 2016 [1855]: 252)

30 Las referencias a los parlamentos coloniales provienen todas de la edición de Gertrudis Payàs 2018. 
lengua; el lenguaraz ${ }^{31}$ sigue teniendo una función central y sus habilidades son reconocidas como tales, no solo en las comunidades, sino también a menudo por el propio Mansilla. (Perna 2016)

El lenguaraz, es decir el intérprete secretario, ocupa la derecha de que hace cabeza. Habla este y el lenguaraz traduce, siendo de advertir que aunque el plenipotenciario entienda el castellano y lo hable con facilidad, no se altere la regla (...) A veces cada interlocutor tiene su lenguaraz, otras es común. El trabajo del lenguaraz es ímprobo en el parlamento más insignificante. Necesita tener una gran memoria, una garganta de privilegio y muchísima calma y paciencia. (II-9)

Esta minuciosa descripción confirma el papel del lenguaraz en tanto garante de la performatividad del parlamento. El lenguaraz -intérprete y secretario- se desenvuelve tanto en lo oral como en lo escrito (Malvestitti 2012), ocupa un lugar muy visible y preciso -a la derecha del que hace cabeza-y cumple con una regla que no se puede alterar, la de estar presente; cada bando tiene su lenguaraz, aunque en ocasiones lo puedan compartir o intercambiar: "Mariano Rosas me cedió su lenguaraz José; colocándose este entre él y yo, y el parlamento empezó" (LIII-301). Generalmente cuando Mansilla describe al lenguaraz que traduce para él dice "mi lenguaraz": "Mi lenguaraz, mestizo, chileno, hijo de cristiano y de india araucana, hombre muy baqueano..." (XII-59), "Mi lenguaraz se puso al habla con el indio... Mora, mi lenguaraz parecía de mal talante..." (XV-78). Al igual que en los parlamentos coloniales, los lenguaraces debidamente nombrados son agentes mediadores de la negociación (Payàs 2012; Malvestitti 2012). Sin embargo, la frecuencia con la que aparece el término de lenguaraz precedido por el posesivo -mí, su- indica una relación casi de pertenencia -el lenguaraz es portavoz de los delegados oficiales de la negociación- ${ }^{32}$, y al mismo tiempo es herramienta de poder en la toma de turnos, sobre todo por parte del bando indígena:

Mariano Rosas creyó engañarme. Estábamos al habla, con tal de esforzar un poco la voz, y siguiendo el plan conocido me destacó un embajador.

31 Ya no se encuentra en los parlamentos de fines del XIX el término de lengua general utilizado durante la Colonia, cayó en desuso. Y el término de intérprete, que encontramos en todos los parlamentos coloniales, tiene, en el texto de Mansilla, una ocurrencia menor que el de lenguaraz.

32 En un testimonio citado por Malvestitti, donde se relata el traslado de unos prisioneros leemos: "Mañana pues se alistan ellos, todos pues van a ir a Chichinales", dijo pues ese comandante, según dijo nuestro lenguaraz" (Malvestitti 2012, p. 73), siendo el lenguaraz en este caso portavoz de una comunidad. 
Ni una palabra de mi lengua entendía este. Era calculado. Se buscaba que sin apelación me valiera del lenguaraz hasta para contestar que sí o que no. Así duraba más tiempo la exposición de mi persona y séquito; se nos examinaba prolijamente. (XXIV-29)

Al contrario del ejemplo anterior, el lenguaraz no está modificado aquí por ningún posesivo sino por un simple anafórico -el lenguaraz-, pero pone de manifiesto el uso estratégico que se le podía dar, una vez iniciado el parlamento: al obligar al coronel argentino a pasar por la mediación del lenguaraz, el cacique Mariano Rosas lo priva de su lengua, el castellano y, mermando su poder de réplica, logra apoderarse del turno de habla. "Dialogue does not presuppose co-operativity" afirma Jan Blommaert (Blommaert 2005: 44), y menos entre dos lenguas dotadas en el mercado lingüístico de tan distinto estatus. Una es lengua de prestigio y poder, la otra lucha por su existencia en un mercado lingüístico regido por un intercambio desigual (Bourdieu 1982). Mansilla está muy consciente de esta desigualdad y de su propio poder discursivo, pero al mismo tiempo aprecia de manera nítida el poder del que disponen los ranqueles en el manejo de su propia lengua, como lo muestra la tipología que nos ofrece de sus modos discursivos en el siguiente fragmento.

\subsubsection{Una tipología conversacional}

Los indios ranqueles tienen tres modos y formas de conversar: La conversación familiar. La conversación en parlamento. La conversación en junta.

La conversación familiar es como la nuestra, llana fácil y sin ceremonias, sin figuras, con interrupciones del o de los interlocutores, animada, vehemente, según el tópico y las pasiones excitadas.

La conversación en parlamento está sujeta a ciertas reglas; es metódica, los interlocutores no pueden, ni deben interrumpirse; es en forma de preguntas y respuestas. (...) Terminado el parlamento, vienen los juicios y discusiones sobre los dotes de los que han sostenido el diálogo. La conversación en parlamento tiene siempre un carácter oficial (...).

[La conversación en junta]. Es un acto muy grave y solemne. Es una cosa muy parecida al parlamento de un pueblo libre, a nuestro congreso, por ejemplo. La civilización y la barbarie se dan la mano. (XXI-112-115)

33 Este fragmento de la obra ha llamado mucho la atención de los comentaristas. Perna retoma íntegramente el pasaje para subrayar las estrategias mnemotécnicas del discurso oral de la sociedad indígena. Ver Perna, Carlos Gabriel 2016. 
Más allá de la confirmación de cierto léxico político, nos interesa destacar la noción misma de "conversación" que nos parece anticipar los estudios contemporáneos del discurso, no solo provenientes de la etnografía de la comunicación (Hymes 1962; Gumperz \& Hymes 1972), del análisis conversacional de mediados del siglo pasado (Sacks, Schegloff, Jefferson 1974), sino también de aquellos que abordan el discurso político desde una perspectiva interaccionista y argumentativa (Kerbrat-Orecchioni 2014; Amossy 2010; Charaudeau 2005; 2017; Adriana Bolivar 2018). Allí radica, a mi juicio, parte de la fuerza que tiene la Excursión para el analista contemporáneo. Si bien Mansilla tiende a representar a lo largo de su texto los tres tipos de conversación mencionados, hace un particular hincapié en el discurso político de las negociaciones, campo donde revela gran parte de sus estrategias argumentativas, como lo vamos a ver a continuación.

\section{DE UNA RETÓRICA A OTRA}

\subsection{El ETHOS DEL POLÍtico}

Mansilla está aún más atento a la gestualidad que acompañaba el discurso de los hablantes, cuando ellos están reunidos en junta, conversando solemnemente en una lengua que no maneja y de la que depende la suerte del tratado de paz:

El cacique general tomó la palabra y habló largo rato, unas veces con templanza, otras con calor, ya bajando la voz hasta el punto de no percibirse los vocablos, ya a gritos; otra accionando, con la vista fija en tierra, ora mirando al cielo. Por momentos, cuando su elocuencia rayaba sin duda en lo sublime, sacudía la cabeza y estremecía el cuerpo como poseído de un ataque epiléptico (...). Las palabras: presidente, Arredondo, Mansilla, yeguas, achucar, yerba, tabaco, plata y otras castellanas que los indios no tienen, flotaban en la peroración a cada rato. (LIII-423)

La elocuencia indígena es un rasgo que ha sido destacado tanto en los primeros parlamentos chilenos -"que son naturalmente retóricos estos indios, y se precian de hacer un buen parlamento" (Paces de Quillín 1641, apud Zaslavsky, Payàs y Carreño, en prensa)- como por viajeros del siglo XIX a 
lo largo y ancho del continente ${ }^{34}$. El énfasis de Mansilla -"Por momentos, cuando su elocuencia rayaba en lo sublime"- contrasta sin embargo con la representación de una gestualidad que se antoja caricatural -"gritos", "ataque epiléptico"-como lo pudimos ver en algunos ejemplos anteriores en los que se retrataba a los ranqueles más cercanos al mundo animal que a lo humano. Con todo, la corporeidad casi cinematográfica en la que inserta el discurso del cacique ranquel nos remite asimismo a una dimensión profunda del lenguaje y la argumentación, a saber, que la gestualidad es parte del habla y constituye uno de los componentes fundamentales del poder de persuasión de cualquier orador.

Las descripciones de Mansilla abundan en analogías y comparaciones, algunas explícitas otras más complejas, sugeridas por una heteroglosia declarada, o por un interdiscurso subyacente. Las primeras pertenecen a un registro clásico de la retórica, las segundas descansan en heterogeneidades enunciativas (Authier-Revuz 1984), que revelan dos tipos de diálogo, dos dimensiones complementarias de la alteridad, el dialogismo interlocutivo y el dialogismo interdiscursivo, permeado por "un exterior discursivo" (Authier-Revuz, 2012:30), es decir el discurso social.

Las comparaciones y analogías suelen ser explícitamente marcadas, ya sea por un morfema gramatical (como) o una palabra semánticamente plena (parecida). Retomando el ejemplo anterior en el que establece la tipología conversacional ranquel: "la conversación familiar es como la nuestra"; [ [La conversación en junta] es "una cosa muy parecida al parlamento de un pueblo libre, a nuestro congreso, por ejemplo. La civilización y la barbarie se dan la mano"; "Todo lo cual prueba que la máquina constitucional llamada por la libertad Poder Legislativo no es una invención moderna extraordinaria; en algo nos parecemos a los indios, o como diría Fray Gerundio...". (XXI112-115)

Las analogías ponen en relación la otredad observada con "lo nuestro", es decir, nuestra manera de hablar, nuestro congreso, nuestra máquina constitucional. Por otra parte, al asociar estas instituciones con la libertad

34 Los ejemplos abundan, pero el ejemplo siguiente nos parece particularmente ilustrativo: "Los mapuches tienen ideas propias respecto de la elocuencia, la que se estudia por ser el camino más seguro para distinguirse. (...) No han faltado escritores españoles que han elogiado altamente la elocuencia araucana; pero, estimada por las reglas clásicas, no merecen las alabanzas exageradas que ha recibido. Sus oradores son muy inferiores a los que se hallan entre los indios de Norteamérica, tanto por la materia como por la elocución de sus discurso..." (Reuel Smith 2016 [1855]: 172-173); lo anterior va exactamente en la línea de Humboldt, quien reconocía a las lenguas nativas en Estados Unidos una gran fuerza de expresión. (Zimmerman 2010: 544) 
-pueblo libre, llamada por la libertad-, el movimiento discursivo de Mansilla es doble. Por un lado, evoca una doxa revolucionaria que sería propia del modernismo de las sociedades "civilizadas", y por otro, les niega su superioridad -"no es una invención moderna extraordinaria", ya que los ranqueles también negocian, cabildean, y "gana la mayoría aunque no tenga razón”. Analogías de este tipo se repiten en muchas partes del texto.

En el último tercio de la Excursión, leemos:

Mariano Rosas, me decía para mis adentros, mientras mi lengua funcionaba, ha firmado el tratado, y lo creía concluido y ahora resulta que lo puede anular. Pues es lo mismo que sucede con el Presidente y el Congreso. ¿No es verdad que el caso era idéntico? Los extremos se tocan. (LIV-305)

Y un poco más adelante, una vez concluida la negociación:

Mariano Rosas y Baigorrita, como dos jefes de partidos, tenían el terreno preparado, la votación segura; pero uno y otro antes de imponer su voluntad habían lisonjeado las preocupaciones populares, ¿No es esto lo que vemos todos los días? ¿La paz y la guerra no se resuelven así? (...) ¿No hacian lo mismo que los que en nombre de la constitución y de las leyes, de la civilización y de la humanidad arman al pueblo contra el pueblo? (...) No hacían lo mismo que los que después de haber sostenido que el pueblo tiene el derecho de equivocarse se han rebelado en contra de él... ¿No mentían? Mariano Rosas y Baigorrita, declarando en una junta, después de haber firmado un tratado de paz, que harían lo que la mayoría resolviese, no imitaban a los que más de una vez han declarado en nuestros Congresos lo contrario de lo que habian convenido en el extranjero? (LV-317)

La analogía, estilísticamente sostenida en la reiteración de varias preguntas, ¿No es verdad que el caso era idéntico? "¿no hacían lo mismo?”, “'No es esto lo que vemos todos los días?”, “no mentían?”, “No imitaban...?”, descansa en los rasgos más negativos de la arena política del mundo "civilizado", como la mentira, el no respeto de los acuerdos, la manipulación, las incoherencias: ellos practican la misma politiquería que nosotros.

Las preguntas reiteradas marcan un dialogismo interlocutivo que se articula en torno a un enunciador colectivo -nosotros y sus derivados-, el cual facilita la emergencia del ethos político de Mansilla. Pero la analogía se nutre aquí de otro tipo de dialogismo, una heterogeneidad constitutiva no marcada, una irrupción del discurso social que nos permite vislumbrar, al menos en estos pasajes, quiénes son los destinatarios de Mansilla. 
El interdiscurso presente en la descripción misma de los políticos ranqueles "como dos jefes de partido", que "tenían el terreno preparado, la votación segura", "lisonjeando las preocupaciones populares", todas expresiones propias del discurso político de las democracias constitucionales, entre las cuales se inscribe la argentina, refuerza la analogía entre las dos tradiciones políticas. Por otra parte, la argumentación de Mansilla cierra con una suerte de aforismos como "la civilización y la barbarie se dan la mano", "los extremos se tocan", frases proverbiales o dichos, "frases sin texto", "proferidas en otros escenarios" sin origen preciso (Maingueneau 2012: 35), que inscriben a la Excursión en lo universal.

¿Quiénes son aquí los destinatarios de Mansilla? Muchas partes de la Excursión sugieren, como ya lo mencionamos, a un destinatario colectivo esencialmente urbano, culto y político, como lo es el propio Mansilla (Ramos 2012). Si bien en las páginas anteriores buscamos, a partir de un análisis de sus estrategias argumentativas, esbozar la figura de un político-militar muy al tanto de la praxis política, el hecho de que la Excursión se percibió y se sigue percibiendo como un texto más literario que político no es casual. Son muchas las partes en las que Mansilla se desenvuelve como literato, invoca la literatura, muestra su manejo de la lengua literaria, de un acervo plurilingüe, estrategia mediante la cual logra también alcanzar a los políticos e intelectuales argentinos.

\subsection{El ETHOS DEL HOMBRE LETRADO}

Como ya lo mencionamos, el texto de Mansilla abunda en digresiones, citas, discursos referidos (DR), bajo todas las modalidades, desde las más explícitas como el discurso directo (DD) e indirecto (DI), citas de todo tipo en español o lengua extranjera, hasta un interdiscurso, que hacen de la Excursión un texto sumamente polifónico, un "nutrido coro de voces cuyos timbres disparejos van desde el más claro al más difuso" (Feldman 2010: 35) en el que el ethos del político se funde con el ethos del literato.

Los fragmentos dialogados son muchos y participan de la dimensión novelística de la Excursión, permitiendo la escenificación de todos los actores, incluyendo al propio Mansilla, al tiempo que constituyen una muestra convincente de los avatares del diálogo interétnico. Estos diálogos desempeñan sin duda en el dinamismo del relato un papel fundamental, pero nos detendremos más bien en esta última parte en otro tipo de heterogeneidades para aprehender el ethos político-literario de Mansilla.

Veamos el siguiente pasaje en el que el coronel, ya al final de su viaje, está negociando con Mariano Rosas la entrega del cautivo Macías: 
Fijó sus ojos en los míos y me dijo textualmente: 'Hermano, el corazón de este hombre es mío'.

¿Qué misterio hay aquí? dije para mis adentros, y como no le contestara y siguiera mirándole, añadió textualmente:

La conciencia de ese hombre es mía. (LVII-328) ${ }^{35}$

El diálogo reproducido aquí podría inscribirse en una "conversación familiar", llevada a cabo en castellano sin mediador alguno entre dos personajes de cultura distinta. Mansilla está creando varias escenas enunciativas: una con Mariano, la otra consigo mismo, y la tercera con sus lectores. Al insertar en dos ocasiones el adverbio modalizador textualmente ${ }^{36}$ para introducir el discurso referido de Mariano Rosas, el enunciador citante Mansilla busca simultáneamente legitimar ante su lector la autenticidad del enunciado referido y resaltar la extrañeza de este mismo discurso. La voz de Mansilla es la que indica cómo entender el enunciado atribuido a Rosas.

En otros casos, la polifonía emerge en el relato mediante una cita literaria, un aforismo, unos versos o sentencias en lengua extranjera:

(1) "El indio vive sobre el caballo, como el pescador en su barca: su elemento es la Pampa (...) A horse, a horse, muy kingdom for a horse!". (XX-107)

(2) "Se inicia con un yapai, que es lo mismo que si dijéramos: "The pleasure of a glass of wine with you? Para que vean los de la colonia inglesa que en algo se parecen a los ranqueles. (XXVI-141)

(3) "Ya ven ustedes, gritaba con toda la fuerza de mis pulmones y mímica indiana (....) Cícerón lo ha dicho: cuasi sermo córporis. Esta vez quedó probado". (LIV- 304)

(4) "[viendo rezar a algunas mujeres] ¿Qué sentimiento las dominaba? Ah, un sentimiento innato al corazón humano. Un sentimiento que Voltaire mismo ha explicado en una frase célebre: Si Dieu n'existait pas il faudrait l'inventer". (LVIII-332)

(5) "Aquella noche comprendí la tendencia irresistible de nuestros gauchos, a apropiarse lo que encuentran en su camino, murmurando interiormente el aforismo de Proudhon: "la propiedad es el robo". (LXVIII)

35 Las cursivas están en el original.

36 En algunas otras partes encontramos la modalización con algunas variantes: casi textualmente; o (textual). 
Los cuatro primeros ejemplos contienen un sintagma en lengua extranjera: los dos primeros funcionando una vez más como "frases sin texto", los dos últimos atribuidos a grandes figuras de la cultura occidental, Cicerón y Voltaire. El último presenta una cita de Proudhon traducida, que el propio Mansilla califica de aforismo. No cabe duda de que el destinatario de estos fragmentos es una vez más el lector culto de Buenos Aires, educado en inglés, francés y latín, así como Mansilla. Ahora bien, regresando a los dos primeros ejemplos, la "frase sin texto" en inglés del 1 viene directamente de Shakespeare (Ricardo III) y la del 2 proviene de algún salón de la élite inglesa. Estas innumerables digresiones que constituyen el "núcleo descentrado de la escritura de Mansilla" (Schvzarzman 2002: 149) aniquilan al etnógrafo para abrir paso al literato culto de salón. Sin embargo, desde el punto de vista argumentativo, le permiten reforzar la analogía entre los bárbaros y los civilizados, que en este caso establece explícitamente con los ingleses: el caballo para el indio de la pampa tiene el mismo valor que para el rey Ricardo III y el gesto ritualizado del yapai es equivalente a "the pleasure of a glass of wine with you" de los salones ingleses. En esta misma tonalidad, cuando Crisostomo, un cautivo que llevaba tiempo entre los indios, le cuenta su historia, leemos: "Lloró y me hizo llorar [habla Crisostomo]. ¿A ti? A mí, pues señor -contestó Crisostomo con un aire que parecía decir: ¿acaso no puedo llorar yo, porque vivo entre los indios?" (XVIII-98). La pregunta que pone en la mirada de Crisostomo es igualmente shakespeariana, haciendo eco al célebre monólogo de Shylock: “¿Y el judío no tiene ojos, no tiene manos, ni órganos, ni alma, ni sentidos, ni pasiones? ¿No se alimenta de los mismos manjares, no recibe las mismas heridas, no padece las mismas enfermedades y se cura con iguales medicinas, no tiene calor en verano y frío en hibierno, lo mismo que el cristiano?". (Acto III, escena 1)

\section{CONCLUSIÓN}

¿Cómo el relato de una misión militar en tierras ranqueles logra impactar a los científicos del Congreso Internacional de Ciencias Geográficas reunido en París en 1875? ¿Cómo este mismo relato logra seducir a los lectores del diario La Tribuna de Buenos Aires, a los literatos argentinos del siglo XX, a los estudiosos de la literatura argentina y a una estudiosa del lenguaje y del discurso político de hoy?

Las múltiples lecturas a las que da pie el relato de la Excursión a los indios ranqueles se deben sin duda a la versatilidad, la sensibilidad y la 
inteligencia de un hombre talentoso. Pero Mansilla produce datos lingüísticos y etnográficos de gran valor. Cierto es que son testimonios de una época, pero siguen siendo muy reveladores de la manera cómo podemos entender hoy las tensiones que se dan entre comunidades indígenas y los partidarios de la modernidad. La defensa de su territorio por los ranqueles del siglo XIX no es muy distinta a la que libran hoy las comunidades indígenas de todo el continente ante la aplanadora desarrollista del mundo globalizado, pese a todos los decretos internacionales sobre el plurilingüismo y el pluriculturalismo reconocidos por los gobiernos nacionales.

La Excursión busca revertir la dicotomía "civilización o barbarie" para luchar de alguna manera contra la exterminación de miles de hombres y mujeres. Mansilla no es la única voz que se levanta. Del otro lado de la Cordillera, varios intelectuales chilenos tratan también de revertir la tendencia a la aniquilación del pueblo araucano ${ }^{37}$. Por más militar que sea, Mansilla es un político que pretende y sabe negociar. Al adentrarse en las estrategias argumentativas de los ranqueles, al establecer analogías con las del mundo occidental, el coronel busca convencer a su auditorio de que las prácticas discursivas del hablante ranquel, del actor político ranquel tanto en interacción con su propia gente como en situación de negociación con el Gobierno argentino, se aparentan con las que se dan en un parlamento inglés o francés. No está demás recordar que la primera evocación de la palabra parlamento para designar el coyagtun de los primeros araucanos la hizo el padre Luis de Valdivia en 1605. Independientemente del cosmopolitismo que caracterizaba tanto a los intelectuales del siglo XVI como a los del XIX, la apreciación que tiene Mansilla de los ranqueles pasa por una sutil observación del manejo que tienen ellos del lenguaje, y la descripción que nos ofrece de sus prácticas discursivas resulta sumamente actual. Sin embargo, pese a sus cualidades de observador y conocedor de las herramientas sociopolíticas que la lengua permite, no son pocas las expresiones en las que se percibe el rechazo, incluso la repulsión hacia los bárbaros, lo cual no debe sorprendernos. El universo discursivo en el que se mueve Mansilla, que es el de un político culto y letrado de su tiempo, viajero cosmopolita

\footnotetext{
37 Jorge Pinto cita varias fuentes periodísticas de mediados del XIX en Chile. En una de estas se lee:

se pide [en la Revista católica] a nuestro gobierno el exterminio de los araucanos, sin más razón que la barbarie de sus habitantes y la conveniencia de apoderarnos de su rico territorio, nuestro corazón latía indignado al presentarse a nuestra imaginación un lago de sangre de los héroes araucanos, y que anhela revolcarse en ella en nombre de la civilización, es un amargo sarcasmo en el siglo en que vivimos (....). (Pinto Rodríguez, 1997. En Leticia Reyna (coord.)).
} 
que pertenece a la elite política del país, y el auditorio variopinto al que se dirige, produce irremediablemente una visión muy heterogénea de este mundo indígena.

\section{REFERENCIAS BIBLIOGRÁFICAS}

AlbuQuerque, Luis. 2011. Crónicas de Indias y relatos de viaje: un mestizaje genérico. En Pilar Latasa (ed.). Discursos coloniales: texto y poder en la América hispana. Madrid: Iberoamericana-Vervuert, pp. 29-43.

Amossy, Ruth (dir.). 1999. Images de soi dans le discours. Delachaux et niestlé: LausanneParis.

2010. La présentation de soi; Ethos et identité verbale. Paris: Presses Universitaires de France.

AnNICK, Louis. 2007, "L'écriture 'non littéraire' d'Arthur Rimbaud, Lucio V. Mansilla et Heinrich Schliemann”, Revue de Littérature comparée, Klincksieck. En línea, https:// www. cairn.inforevue-de-litterature-comparee-2007-4-page-439.htm

Austin, J. L. y J. O. Urmson, (comp). 1982. Cómo hacer cosas con palabras: palabras y acciones. Barcelona: Paidos.

Authier-Revuz, JacQueline. 1984. Hétérogénéité(s) énonciative(s). Paris: Langages 73: 98-111.

2012. Dire à l'autre dans le déjà dit: interférences d'altérité -interlocutive et interdiscursive - au coeur du dire. En Lorda Mur y Clara Ubaldina (coord.). Polifonía e intertextualidad en el diálogo. Madrid: Arco-libros, pp.19-45.

Barros Arana, Diego. 1934. Orígenes de Chile. Santiago: Nascimento.

Benveniste, Emile. 1977. Problemas de lingüística general, II. México: Siglo XXI Editores. Traducción: Juan Almela.

Blommaert Jan. 2005. Discourse, a critical introduction. Cambridge: University Press.

Bolívar, Adriana. 2018. Political Discourse as Dialogue. A Latin-American Perspective. Oxford, UK: Routeledge.

Bourdieu, Pierre. 1982. Ce que parler veut dire. Paris: Fayard.

Caillet-Bois, Julio. 1947. Una excursión a los indios ranqueles. Prólogo, notas y edición de Lucio V. Mansilla. México: FCE.

Charaudeau, Patrick. 2017. Le débat public. Limoges: Lambert-Lucas. 2005. Le Discours politique. Paris: Vuibert.

2003 [1997], El Discurso de la Información; la construcción del espejo social. Barcelona: Gedisa.

Congrès International des Sciences géographiques, tenu à Paris du 1 au 11 août 1875 : compte rendu des séances. 1880, volume second, BNF, pp. 322; 340. Fuente: gallica. bnf.fr / Bibliothèque nationale de France.

De Valdivia, Luis. 1612. [Carta de Luis de Valdivia al Rey Felipe III]. En Payàs, G. 2018. Los Parlamentos Hispano-Mapuches 1593-1803. Textos fundamentales. Temuco: UC ediciones.

Delaporte, Henry. 2016 [1855]. En Italo P. Salgado (comp.), pp. 243-261.

Di Steffano, María y María Cecilia Perreira. 2017. Polifonía. En M. ${ }^{a}$ Cecilia Perreira (coord.). Semiología. Cuadernillo 2. Buenos Aires: Sede Ciudad Universitaria. 
Feldman, Hernán. 2010. Una excursión a los indios ranqueles de Lucio V. Mansilla. Hispamérica 115: 25-36.

Gumperz, J. J. y H. Hymes Dell. 1972. Directions in sociolinguistic: the ethnography of communication. New York: Holt, Rinehart and Winston.

JAKOBSON, RomÁn. 1975. En torno a los aspectos lingüísticos de la traducción. Ensayos de Lingüística General, pp. 67-77. Barcelona: Seix Barral.

Kerbrat-Orecchioni, Catherine. 2001. Les actes de parole dans le discours. Paris: Naathan. 2014. De l'analyse du discours à l'analyse des discours. En Jean Claude Soulages (dir.). L'analyse de discours. Rennes: Presses Universitaires de Rennes.

Krieg Alice. 1996. Jacqueline Authier-Revuz, Ces mots qui ne vont pas de soi. Boucles réflexives et non-coïncidences du dire. Mots 47. Paris, pp. 149-154; https://www.persee. fr/doc/mots_0243_450_1996_num_47_1_2092

Louis, Annick. 2007. HOMO EXPLORATOR. L'écriture "non littéraire" d'Arthur Rimbaud, Lucio V. Mansilla et Heinrich Schliemann. Klincksieck | Revue de littérature comparée, $\mathrm{n}^{\circ} 324$ | pp. 439-458. https://www.cairn.inforevue-de-litterature-comparee-2007

Maingueneau, Dominique. 2015. Argumentation et scénographie. In Carmen PineiraTresmontant. Discours et effets de sens. Argumenter, manipuler, traduire. Arras: Artois Presses Université, 71-87.

2014. Retour critique sur l'éthos. Langage et société 149: 31-48.

2010. El enunciador encarnado; la problemática del Ethos. Versión 24: 203-225.

2012. Les phrases sans texte. Paris: Armand Colin.

1999. Ethos, scénographie, incorporation. En Ruth Amossy (dir.). Pp.75-100.

Malvestiti, Marisa. 2012. Mediación lingüística al Este de los Andes en la época del Awkan (fines del siglo XIX). En Gertrudis Payàs y José Manuel Zavala. La mediación lingüísticocultural en tiempos de guerra. Temuco: Ediciones UC de Temuco.

Mansilla, Lucio V. 2012. El excursionista del planeta; escritos de viaje. Selección y prólogo de Sandra Contreras. Buenos Aires: FCE.

1947 [1870]. Una excursión a los indios ranqueles. Edición, prólogo y notas de Julio Caillet-Bois. Fondo de Cultura Económica: México-Buenos Aires.

Marimán Quemado, Pablo. 2006. Los Mapuches antes de la conquista militar chilenoargentina. En Pablo Marimán; Sergio Caniuqueo; José Millalén; Rodrigo Levil. i;Escucha, winka..!! Santiago: Lom Ediciones, pp. 53-127.

Molloy, Sylvia. 1996. Imagen de Mansilla. En Saúl Sosnowski. Lectura crítica de la literatura americana. Venezuela: Biblioteca Ayacucho, pp. 392-404.

Nieto, Maritza y Pablo Segovia. 2018. Ethos y análisis del discurso desde la perspectiva francesa. Concepción: Onomázein.

PAYÀs, GeRTRUdis. 2018. Los parlamentos hispano-mapuches. Textos fundamentales. Versión para la lectura actual. Santiago y Temuco: Ed. Universidad Católica de Temuco, DIBAM y Centro de Investigaciones Diego Barros Arana.

, RAmón Curivil y José Quidel. 2012. Birreferencialidad en la traducción de términos clave de las negociaciones hispano-mapuches. Algunos ejemplos extraidos de la Actas de los Parlamentos del periodo de Ambrosio O’Higgins (1770-1803). Mutatis Mutandis 5 (2): 249-258.

, José Manuel Zavala y Mario Samaniego. 2012. Al filo del malentendido y la incomprensión: el padre Luis de Valdivia y la mediación lingüística. Historia 1 (45): 69-90.

Perna, Carlos Gabriel. 2016. El lenguaraz y la comunicación en la frontera argentina en el siglo XIX. Lexis, vol. 40 (1): Lima.

Pinto Rodríguez, Jorge. 1997, "Del antiindigenismo al proindigenismo en Chile en el siglo XIX”, En Leticia Reyna (coord.). México: Siglo XXI, pp.137-157. 
Popolizio, EnRIQue. 1966. Prólogo a Mansilla, Lucio V. Una excursión a los indios ranqueles. Buenos Aires: Universitaria.

Pratt, Marie Louise. 1992. Imperial Eyes. Travel writing and Transculturation. London and New York: Routeledge.

Rabatel, Alain. 2004. L'effacement énonciatif et discours rapportés. Langages 156: 3-17.

Ramos, Julio. 2012. Entre otros: Una excursión a los indios ranqueles de Lucio V. Mansilla. En línea, http://literaturaargentinal unrm.files.wordpress.com/2012/06/ramos-julio

SACKs, H., E. A. Schegloff, \& G. JefFerson (1974). A simplest systematics for the organization of turn-taking for conversation. Language 50: 696-735.

Salgado, Ítalo P. 2016. (comp.). Lorena Villegas y Samuel Quiroga (inv.). Travesías por la Araucanía; Relatos de viajeros de mediados del siglo XIX. Temuco: Universidad Católica de Temuco Ediciones.

Sarmiento, Domingo F. 1977 [1845]. Facundo o Civilización y Barbarie. Ayacucho: Biblioteca Ayacucho.

Salvioni, Amanda. 2015. El silencio de las imágenes. Las ilustraciones a Una excursión a los indios ranqueles. Confluenze, vol. 7 (1), Bologna. Pp. 107-136.

Schvzarzman Julio. 2002. Luicio V. Mansilla y la orgía ranquel. Cahiers du CRICCAL. 28. Pp. 147-154.

Smith, Reuel. 1914. En Italo P. Salgado (comp.). Lorena Villegas y Samuel Quiroga (inv.). 2016. Travesías por la Araucanía; Relatos de viajeros de mediados del siglo XIX. Temuco: Universidad Católica de Temuco Ediciones.

2016 [1855]. Los araucanos. Notas sobre una gira efectuada entre las tribus indígenas. En Ítalo P. Salgado (comp.), Lorena Villegas y Samuel Quiroga (inv.). Travesías por la Araucanía; Relatos de viajeros de mediados del siglo XIX. Temuco: Universidad Católica de Temuco, pp. 123-242.

Van Dijk, Teun. 1980. Estructuras y funciones del discurso. México: Siglo XXI.

Whorf, Benjamin Lee. 1966 [1956]. Language Thought \& Reality. Cambridge: M.I.T. Press

VIÑAS, DAVID. 1982. Indios, Ejército y Frontera. México: Siglo XXI Editores. 1971. De Sarmiento a Cortázar. Buenos Aires: Siglo Veinte.

ZASLAVSKY, D., G. PAYÀs, I. CARREÑo. 2019. Vicisitudes de algunas equivalencias en el discurso de la diplomacia hispano-mapuche en el Chile colonial. Meta 64 (3). Montreal.

Zavala, José Manuel. 2011. Los mapuches del siglo XVIII. Temuco: UC ediciones.

Zimmerman, Klaus. 2010. La percepción de las lenguas indomexicanas en Wilhelm von Humboldt: entre glotocentrismo, interculturalidad y método comparativo. En Karl Kohut; Alicia Mayer; Brígida von Mentz; Ma.Cristina Torales. Alemania y el México Independiente; percepciones mutuas. México: Herder, pp. 529-550. 